\title{
Anatomy and techniques in posterior urethroplasty
}

\author{
Reynaldo G. Gomez ${ }^{1,2}$, Kyle Scarberry ${ }^{3}$ \\ ${ }^{1}$ Department of Urology Service, Hospital del Trabajador, Santiago, Chile; ${ }^{2}$ Universidad Andres Bello School of Medicine, Santiago, Chile; ${ }^{3}$ Urology \\ Institute, University Hospitals Cleveland Medical Center, Cleveland, $\mathrm{OH}$, USA \\ Contributions: (I) Conception and design: RG Gomez; (II) Administrative support: RG Gomez; (III) Provision of study materials or patients: RG \\ Gomez; (IV) Collection and assembly of data: All authors; (V) Data analysis and interpretation: All authors; (VI) Manuscript writing: All authors; (VII) \\ Final approval of manuscript: All authors. \\ Correspondence to: Reynaldo G. Gomez. Department of Urology Service, Hospital del Trabajador, Ramon Carnicer 185, 7500000 Santiago, Chile. \\ Email: gomez.reynaldo@gmail.com.
}

\begin{abstract}
Given its complex anatomy, injury to the posterior urethra may result in a number of reconstructive challenges. With the appropriate operative planning and experience, surgical repair can be very successful. This review discusses the applicable techniques for the perineal approach to posterior urethral stenosis, including bulbomembranous anastomosis for pelvic fracture urethral injury and repair of vesicourethral anastomotic stenosis (VUAS) following prostate surgery. The advanced techniques reviewed include an adaptation allowing a bulbar artery sparing approach to posterior urethroplasty and an intrasphincteric urethroplasty procedure which may allow continence preservation in patients with membranous urethral stenosis.
\end{abstract}

Keywords: Posterior urethral reconstruction; posterior urethroplasty; pelvic fracture urethral injury

Submitted Dec 01, 2017. Accepted for publication Mar 05, 2018.

doi: $10.21037 /$ tau.2018.03.05

View this article at: http://dx.doi.org/10.21037/tau.2018.03.05

\section{Introduction}

Stenosis of the posterior urethra (PUS) can result from pelvic trauma or treatment of prostatic diseases. Conservative management with dilation and/or endourologic procedures can be highly successful; however, failures will require open reconstruction.

Surgery of the posterior urethra is one of the most challenging reconstructive scenarios in the lower urinary tract due to its deep location in the pelvis, association with the pelvic bone and ligaments, and close relation to complex anatomic structures, including the prostate and the urinary sphincter. More than in any other segment of the urethra, posterior urethral surgery requires experience and a comprehensive knowledge of the local anatomy and functional particularities of the involved organs.

Cumulated experience and understanding of the surgical anatomy of the urethral blood supply and external urinary sphincter allows the surgeon to introduce refinements to the different reconstructive techniques and optimize the surgical approach.

We discuss here the most relevant anatomic and functional features of the posterior urethra and examine the different reconstructive options available to restore its patency.

\section{Anatomy of the male posterior urethra}

The adult male urethra is an $18-20 \mathrm{~cm}$ tubular conduit that extends from the bladder neck $(\mathrm{BN})$ to the urethral meatus $(1,2)$. The urethra is subdivided into the anterior and posterior segments at the level of the perineal membrane, where the posterior urethra ends at the proximal corpus spongiosum (Figure 1).

The relatively short posterior urethra (approximately $4 \mathrm{~cm}$ ) contributes to the urogenital sphincter mechanism. The posterior urethra is subdivided into 3 segments: the preprostatic urethra, prostatic urethra, and membranous urethra $(2,3)$.

The first $1 \mathrm{~cm}$ of the posterior urethra, extending from 


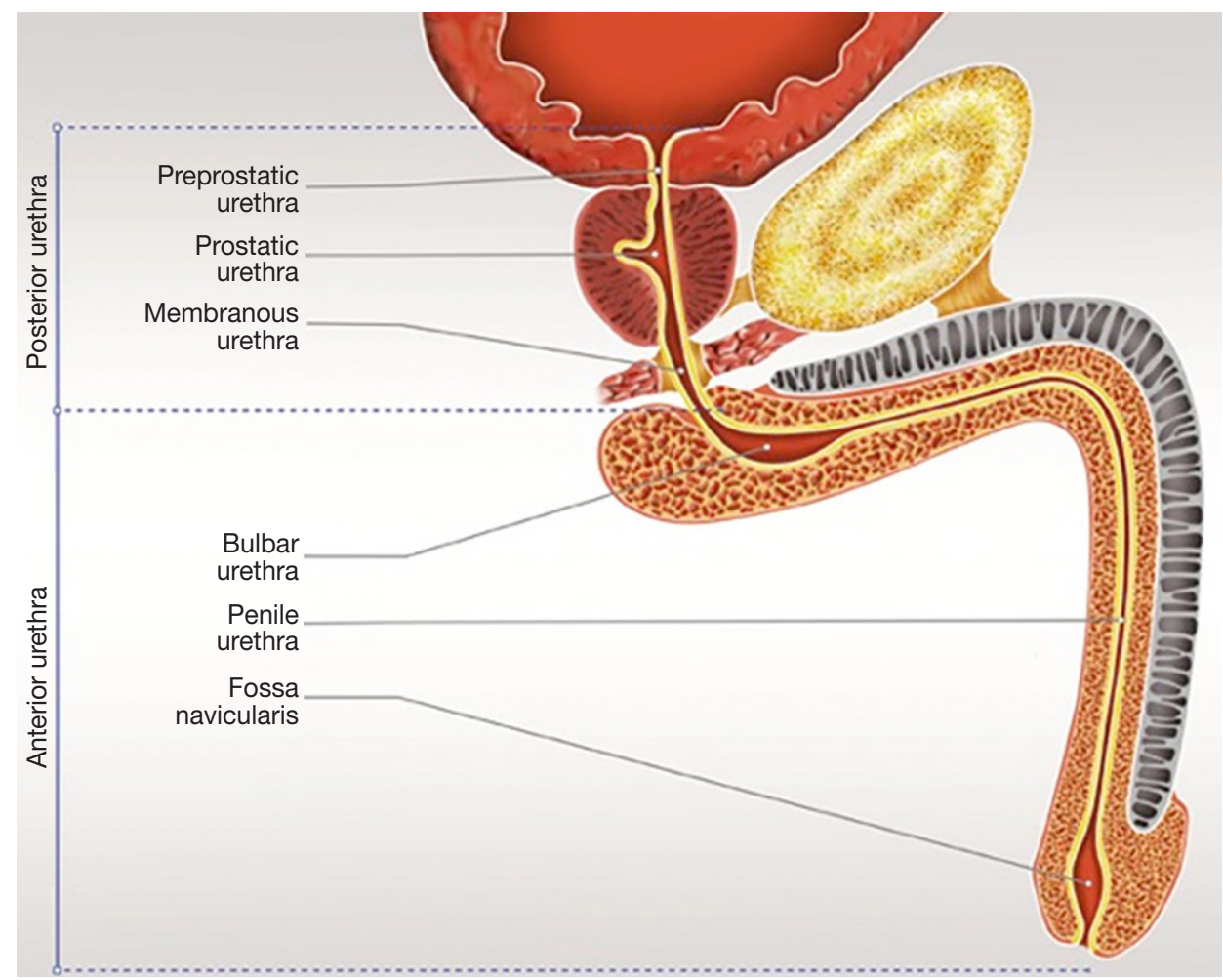

Figure 1 Divisions of the urethra.

the bladder base, is the preprostatic urethra. It contains the internal sphincter mechanism as well periurethral gland tissue which can contribute to benign prostatic hyperplasia $(\mathrm{BPH})(2,4)$.

The prostatic urethra runs $3-4 \mathrm{~cm}$ in length through the anterior prostate gland, making an approximately $35^{\circ}$ turn. The paired ejaculatory ducts drain lateral to the prostatic utricle into the verumontanum (3). The verumontanum serves as an important landmark during transurethral resection of the prostate (TURP) because striated muscle fibers are located just distal to this location and resection beyond this point may result in damage to the external sphincter. The prostatic urethra is immobilized distally due to its fixation to the anterior pubic arch by the paired puboprostatic ligaments (2).

The membranous urethra (approximately $1.5 \mathrm{~cm}$ in length) is located about $2.5 \mathrm{~cm}$ postero-inferior to the symphysis pubis and traverses the perineal membrane. The membranous urethra is at particular risk for injury due to its lack of distensibility and the absence of protective surrounding spongy tissue or prostatic parenchyma (5). The wall of the membranous urethra is comprised of an epithelial lining, a fibroelastic connective tissue, and an outer muscle coat. The outermost muscle layer is comprised of circularly-orientated striated muscle, which functions as the external urethral sphincter or rhabdosphincter. The bulbourethral glands are located within these circular muscle bundles and secrete fluid into the membranous urethra during sexual arousal (2).

Abnormal narrowing of the anterior urethra is typically associated with some degree of spongiofibrosis, but the posterior urethra has no surrounding corpora spongiosum. As such, narrowing of the anterior urethra is referred to as urethral "stricture" whereas narrowing of the posterior urethra is referred to as "stenosis".

\section{Sphincteric control of urinary continence}

The urethral sphincter complex, comprised of the internal lissosphincter and an external rhabdosphincter, acts to control urinary continence. The lissosphincter is primarily composed of smooth muscle and is most prominent at the $\mathrm{BN}$, with muscle fibers thinning distally along the posterior urethra. The rhabdosphincter is composed mainly of skeletal muscle, is most pronounced surrounding the membranous urethra, and becomes less distinct proximally (6). The lissosphincter is primarily responsible for continence 
at rest, whereas the rhabdosphincter functions to control active continence during straining and the propulsion of semen during ejaculation (6). Although either sphincter can maintain passive continence, the striated component typically assists only with active continence (e.g., interruption of voiding) when both mechanisms are functionally intact (1).

The lissosphincter provides passive continence via tonic sympathetic activity (5). Its smooth muscle bundles are oriented circularly, surrounding the $\mathrm{BN}$ and preprostatic urethra (7). Contraction of this sphincter maintains continence and prevents retrograde flow of semen into the bladder during ejaculation. Disruption of the internal sphincter following BPH surgery, such as TURP, results in retrograde ejaculation (2), but urinary continence is maintained by the intact external sphincter.

The external rhabdosphincter is typically $2 \mathrm{~cm}$ in length, surround the membranous urethra, and provides urethral tone under involuntary control. This tone results in the membranous urethra being the point of highest intraurethral pressure. Support is also provided by the voluntary control of the extrinsic periurethral striated muscle, namely the pubourethral part of the levator ani muscle (5). The external sphincter is capable of maintaining passive urinary continence via sustained contraction of slow twitch fibers if the internal sphincter is compromised by BPH surgery (2).

Recent anatomical studies show the rhabdosphincter is separated from the anterior and lateral aspects of the membranous urethra by a thin connective tissue sheath. This can allow surgeons to separate the sphincter muscles from the urethral wall without damaging either structure (8).

\section{Arterial blood supply of the urethra}

The paired bulbar arteries arise from the internal pudendal arteries and pierce the perineal membrane to supply blood to the bulb of the corpus spongiosum. The anterior urethra has a dual blood supply, which can be maintained by retrograde flow from the dorsal penile artery via the corpus spongiosum if antegrade blood supply is lost due to bulbar artery transection.

\section{Posterior urethroplasty for pelvic fracture urethral injuries (PFUI)}

\section{Anatomy of PFUI}

For decades, it was commonly believed that pelvic fracture resulted in injury to the posterior urethra at the prostatomembranous junction. However, current evidence suggests most injuries are located at the bulbomembranous junction. Bulbomembranous junction injury commonly occurs due to the close proximity of the membranous urethra to the pubic rami and symphysis, urethral fixation via the puboprostatic ligaments and urogenital diaphragm, and lack of supportive prostatic or spongiosal tissue. Therefore, posterior urethroplasty for PFUI is most accurately named a bulbomembranous anastomosis (BMA).

\section{BMA planning}

Bulbomembranous anastomosis is the standard surgical approach for reconstruction of PFUI stenosis or obliteration, but appropriate selection of surgical approach and technique requires thorough preoperative evaluation.

\section{Preoperative consideration for PFUI reconstruction}

A thorough preoperative assessment begins with a complete history. The history should include the presence of erectile dysfunction (ED), which is most commonly due to associated traumatic nerve injury (9). Pre-operative pharmacodynamic penile Doppler studies should be considered in patients with ED to assess for penile arterial insufficiency. In cases of arterial insufficiency, penile microvascular revascularization surgery has been advocated prior to urethroplasty to avoid necrosis and ultimate reconstructive failure $(10,11)$.

Clinical examination is performed to assess the involved tissues. Assessment of penile skin integrity, degree of scarring in the perineum, presence of cutaneous fistula, and persistent hematoma or abscess on rectal examination is of particular importance. Conventional radiological staging includes a voiding cystourethrogram (VCUG) and a retrograde urethrogram (RUG). This "up and down urethrography" provides assessment of the integrity of the $\mathrm{BN}$, length of the urethral defect, and the length of unaffected bulbar urethra available for repair. A closed BN on cystography indicates indemnity of the internal sphincter mechanism and is predictive of adequate postoperative urinary continence. On the contrary, an open $\mathrm{BN}$ may be the result of a traumatic tear at this level or indicative of a concurrent traumatic injury to the sacral plexus, usually resulting from a fracture compromising the sacral foramina. Since the external sphincter is likely to be compromised during a membranous urethral injury, BN dysfunction 
confers a high risk of post-BMA urinary incontinence. Although an open $\mathrm{BN}$ on preoperative urethrography is not always predictive of incontinence, this finding warrants a careful preoperative evaluation and patients should be counseled accordingly (12).

Contrasted magnetic resonance imaging (MRI) can be successfully used to evaluate the length of the urethral defect and the degree of lateral displacement of the prostate $(13,14)$. Perioperative antibiotics should be administered based on urine culture results.

BMA is typically delayed for 3-6 months following the initial injury in order for acute hematoma resolution and maturation of fibrotic tissues $(15,16)$. However, we have experience performing reconstruction as early as 3-6 weeks following PFUI if the associated injuries are stable, the perineum is soft on palpation (no hematoma or abscess), and the patient is able to be safely placed in the dorsal lithotomy position (17).

\section{BMA technique}

\section{Patient positioning}

The standard lithotomy position is routinely utilized for BMA. Many centers advocate the use of the exaggerated lithotomy position $(18,19)$ citing improved and more direct perineal exposure. There is mounting evidence that the exaggerated lithotomy position is associated with neuropraxia injury of the lower limbs and even rhabdomyolysis and acute renal failure (20-23). The use of a beanbag without adequate gel padding and operations lasting greater than 5 hours increase the risk of complications associated with exaggerated lithotomy (20).

\section{Exposure of the bulbar urethra}

The bulbar urethra is exposed using a midline incision extending from the perineo-scrotal junction to approximately $1 \mathrm{~cm}$ from the anal verge. An inverted "Y" shaped lambda incision is utilized by some surgeons and may offer additional exposure, but has the potential for increased wound complications (24).

\section{The step-wise perineal approach}

The bulbospongiosus muscle is identified and split in the midline. This surgery is highly facilitated by a static ring retractor such as the Dennis-Browne, the Scott (Lone-Star) retractor, or the Bookwalter-Jordan. Webster and Ramon popularized a step-wise perineal approach for BMA(25), with individual techniques first described by Marion (26),
Paine and Coombes (27), and Waterhouse (28). These step-wise maneuvers provide the necessary bulbar urethral length to obtain a tension-free anastomosis:

\section{Bulbar urethral mobilization}

The bulbar urethra is dissected free from the perineal body and overlying corpus cavernosum proximally to the site of obliteration. The bulbar arteries are ligated. Distally the mobilization proceeds as far as necessary, taking into consideration that excessive dissection distal to the penoscrotal junction may cause penile chordee.

\section{Crural separation}

The corpora cavernosa are separated in the midline using either sharp scissors or electrocautery. This virtual space can be developed by separating the corpora, allowing the urethra to lie between the crura, to decrease the travel distance to the proximal urethral end.

\section{Inferior pubectomy}

A wedge of the inferior pubic bone is excised using rongeurs. This is performed by retracting the crura laterally using a periosteal elevator, with identification and ligation of the dorsal vein performed.

\section{Supracrural rerouting}

If inferior pubectomy does not allow a tension-free anastomosis, some surgeons route the urethra supracrurally after creating a space between the left or right crus and the anterior surface of the pubic bone.

Utilization of bulbar urethral mobilization and crural separation only is classified as a simple perineal approach. The inclusion of either inferior pubectomy or supracrural rerouting is described as an elaborated perineal approach (29).

\section{Bulbomembranous anastomosis}

The urethra is transected and all scar tissue is dissected free until healthy edges of proximal urethra are identified. A curved sound is placed via the suprapubic tract into the proximal urethra to guide dissection. For optimal outcomes, each urethral end should be clear of fibrosis, display healthyappearing mucosa, and be able to accommodate a 28 French bougie. Removal of post-traumatic perineal fibrosis is probably the most challenging and critical stage of this operation. Resorption of the pelvic hematoma usually leaves a dense fibrous scar in the perineum that requires complete excision. In fact, the primary cause of reconstruction failure is likely failure to adequately remove scar tissue from the free urethral ends. Once free of fibrosis, the anastomosis is typically performed with six 5-0 monofilament absorbable sutures (poliglecaprone) placed circumferentially and tied down in a parachute fashion. 
A 16 French silicone urethral catheter is left for 2-3 weeks and removed if pericatheter urethrography does not reveal any extravasation.

\section{Outcomes following elaborated approach for insufficient urethral length \\ Inferior pubectomy}

While urethral mobilization and crural separation are routinely performed, rates of inferior pubectomy during BMA are reported from as low as $10 \%(18,19,30,31)$ to as high as 30-64\% (32-35) in different series. This discrepancy may relate to the mechanism of initial injury, as one study found these rates varied between two different countries. Inferior pubectomy was performed in $66 \%$ of Indian patients, where mechanism of injury was largely due to pedestrian, bicycle, motorcycle, and agricultural injuries. Only $24 \%$ of Italian patients underwent inferior pubectomy, where injuries primarily resulted from less traumatic motor vehicle accidents (36). Italian patients also had a higher rate of primary urethral alignment, which has been claimed to result in less severe urethral stenosis.

\section{Supracrural rerouting}

Supracrural rerouting may provide an additional $2 \mathrm{~cm}$ of length for extended urethral gaps inadequately bridged using inferior pubectomy in the progressive perineal approach (25). However, many surgeons observed this step to rarely be necessary (18). In a multicenter study of 145 patients, supracrural rerouting was utilized in only 4 patients, of whom 3 (75\%) developed recurrent stenosis (31). Similarly, Hosseini et al. found supracrural rerouting was performed in 11 of 200 patients $(5.5 \%)$, of whom $64 \%$ failed. They concluded that supracrural rerouting should be used with caution due to the high rate of restenosis $(30,37)$.

\section{Abdominoperineal approach}

In very unusual circumstances, most commonly involving re-do cases, the first 4 steps do not provide adequate access to the prostatic apex and a transpubic (abdominoperineal) approach may be required (38).

\section{Preoperative investigations to predict which techniques are required}

Whether surgeons are able to determine the appropriate surgical approach (simple perineal/elaborated perineal/ abdominoperineal) based on preoperative staging studies (RUG/VCUG/MRI) is controversial. Andrich et al. demonstrated that the urethral defect, as visualized on RUG and VCUG, is not predictive of the required type of repair (38). This is likely due to PFUI being associated with an upward displacement of the bladder and prostate. They recommend that any surgeon planning to repair such an obliteration or stenosis should be experienced with all the described steps, as the procedure may require any one step. On the other hand, Koraitim suggested that a simple perineal repair may suffice for gaps of $2.5-3.0 \mathrm{~cm}$ in length, and larger gaps will require an elaborated perineal repair $(29,39)$.

The length of the urethral defect can be predictive of the type of repair required. Koraitim described the gapometry/ urethrotomy index (GUI) as the length of the urethral gap relative to the length of the bulbar urethra (from the blind proximal end to the bulbopenile junction) (40). He concluded a GUI of less than 0.35 indicates a simple perineal repair, whereas a GUI greater than 0.35 requires more complex surgery. In addition to the GUI, he found the urethral gap length and the degree of lateral prostatic displacement were also independent predictors of the type of repair required. A GUI cut-off of 0.35 provided a respective sensitivity, specificity and accuracy of $90 \%, 91 \%$ and $90 \%$ (41). However, this index retains two distinct disadvantages. First, the length of the urethra potentially varies with the angle of the patient or X-ray during positioning for RUG. Second, in most cases the distal limit of the bulbar urethra "at the bulbopenile junction" is highly uncertain. For these reasons, this index has found very limited clinical application.

However, in clinical practice the vast majority of injuries are less than $2 \mathrm{~cm}$ in length and ultimately can be reconstructed utilizing the simple perineal approach.

\section{$B M A$ with sparing of the bulbar arteries}

BMA typically requires detachment of the perineal membrane at the site of the bulbomembranous urethral injury, which requires division of the bulbar arteries. The distal spongiosal stump then becomes reliant on retrograde flow from the glans and perforating arteries via the dorsal artery of the penis. If the penile artery blood supply is compromised by the pelvic fracture injury, bulbar artery transection may result in penile arterial insufficiency and urethral ischemia. This is an infrequent but known cause of BMA failure as it can result in bulbar urethral stricture distal to the repair, and penile revascularization has been recommended to prevent this complication. Moreover, some of these patients may be at risk for post-traumatic urinary incontinence requiring placement of an artificial urethral sphincter (AUS). Division of the bulbar arteries may limit 


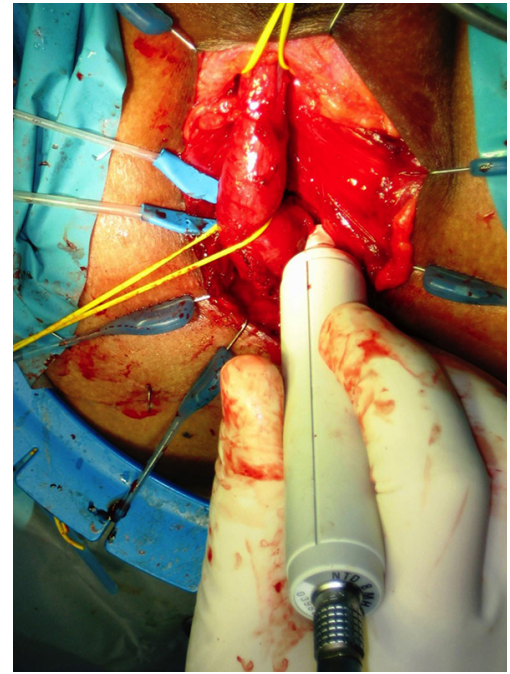

Figure 2 The Doppler stethoscope is used to locate the bulbar arteries. With permission from Elsevier (43).

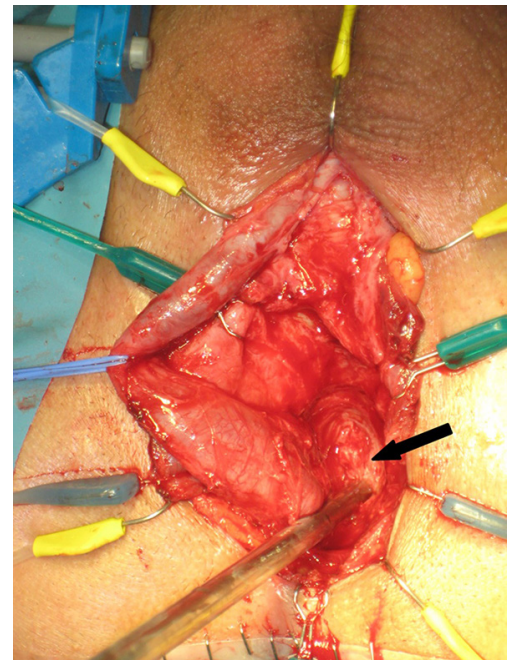

Figure 3 The bulb has been mobilized dorsally and from the left side, the crura have been split, and the left bulbar artery divided, exposing the scar to be resected (arrow). With permission from Elsevier (43).

spongiosal blood flow, placing these patients at higher risk of AUS erosion. In 2007, Jordan et al. first described a bulbar artery sparing approach to excision and primary anastomosis for proximal bulbar urethral strictures (42). We have modified this technique for PFUI to assist in avoiding ischemic failure of the reconstruction (43).

\section{Bulbar artery sparing technique}

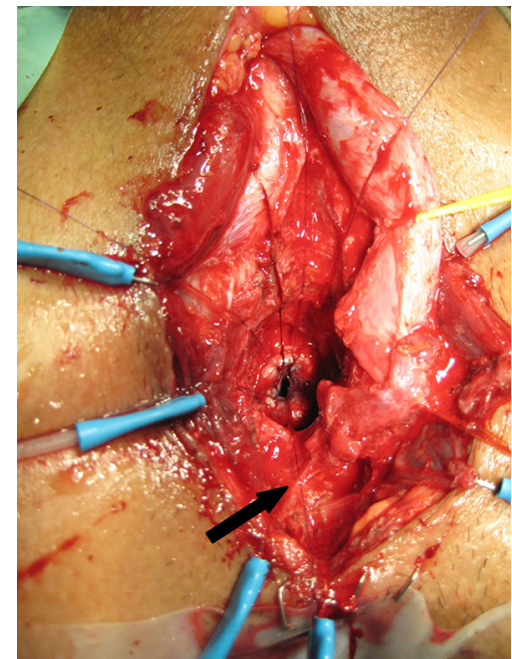

Figure 4 Here a right-sided approach has been chosen; the bulb is retracted to the left, the scar has been removed, and the proximal urethra is ready for anastomosis. Note the bulb remains attached to the perineum (arrow). With permission from Elsevier (43).

Following midline opening of the bulbospongiosus muscle, a Doppler ultrasound stethoscope is used to locate the bulbar arteries (Figure 2). The artery with the lower Doppler signal is preferentially sacrificed in order to preserve the artery with the more robust signal. Next, the bulbar urethra is mobilized dorsally and from one side, without detachment of the bulb from the perineal body, utilizing vessel loops for lateral retraction of the urethra (Figure 3). The intercrural septum is opened widely, the scar tissue is removed in its entirety, and the usual exposure of the apical prostatic urethra is obtained. No contralateral dissection is performed allowing preservation of the remaining bulbar artery. An end-to-end anastomosis is then performed in a tension-free fashion (Figure 4). Doppler ultrasound is again utilized to verify preservation of the spared bulbar artery.

\section{Bulbar artery sparing BMA outcomes}

We previously reported our series of 26 patients who underwent bulbar artery-sparing BMA for PFUI. All patients were voiding normally and stricture-free at a mean follow-up of 20 months (43).

This non-transecting technique is applicable to most PFUI patients and not restricted to those with short urethral gaps. In fact, a tension-free anastomosis was possible in all cases in our series, even with distraction 
defects as long as $4.5 \mathrm{~cm}$. Localization of the bulbar arteries with Doppler ultrasound is a crucial portion of the procedure given the significant variation in bulbar artery anatomy $(44,45)$. Significantly, three patients in our series only had one identifiable bulbar artery that was patent. We were able to perform bulbar artery sparing BMA in all patients in our series with one artery preserved in 18 patients and both preserved in 7 .

\section{Reconstructive options for failed BMA}

Multiples series have reported long-term success rates of 90-98\% for primary urethral reconstruction following PFUI $(18,19,30,31,46,47)$. Failure of BMA presents a formidable challenge and requires extensive surgical expertise with comprehensive knowledge of a wide variety of techniques.

The integrity of the bulbar urethra is a main determinant of the type of procedure that will be required. Depending on the degree of loss of the bulbar urethra from ischemic necrosis, a single repair may not be possible and a staged urethroplasty should be considered.

\section{Outcomes of re-do urethroplasty for PFUI}

While primary BMA success rates exceed $90 \%$ in many studies, re-do urethroplasty outcomes have been met with contradictory results. Culty et al. reported a success rate of $60 \%$ for patients who underwent BMA after prior urethral manipulation as compared to $90 \%$ success rates for patients who underwent primary repair $(48,49)$. Singh et al. also reported worse outcomes for re-do perineal BMA (50). Others have reported success rates of $84-92 \%$ for patients undergoing re-do urethroplasty (51-53), though the transpubic approach was utilized in $30-40 \%$ of patients.

\section{Urethroplasty for posterior urethra stenosis (PUS) following prostate surgery}

\section{Preoperative considerations}

Evaluation for this patient population includes a detailed account of symptoms, oncologic and performance status, previous treatments, and co-morbidities. Good quality retrograde and voiding "up and down" cystourethrography is again essential to locate and delineate the affected anatomy. Cystoscopy allows evaluation of the quality of the urethra and sphincteric function in addition to allowing identification of any calcifications, seed implants, vascular clips, or other foreign body material. CT and MR may be useful in complex scenarios such as concomitant rectourethral fistula. A urodynamic study can be performed when a small capacity or overactive bladder is suspected, such as in patients with a history of radiation or combination therapy.

\section{Continence preservation in bulbomembranous stenosis patients with previous BPH surgery}

Patients with removal of the internal sphincter mechanism by previous TURP or open simple prostatectomy (OSP) are at risk for incontinence following BMA. Utilizing the relatively recent anatomic discovery of the connective tissue sheath between the membranous urethra and the external rhabdosphincter, we developed a novel technique for intersphincteric bulbo-prostatic anastomosis that allows separation of the muscle from the urethral wall, enabling a sphincter-preserving primary anastomosis (8).

\section{Intrasphincteric bulbo-prostatic anastomosis (ISBPA) technique}

Splitting of the bulbospongiosus muscle, bulbar mobilization (without detachment from the perineal body), and crural splitting are performed as described previously. The urethra is elevated with two vessel loops. A third vessel loop is used to retract the bulbar vessels posteriorly as described by Jordan et al. (Figure 5).

The membranous urethra is secured using a fourth vessel loop. The sheath surrounding the membranous urethra is then opened circumferentially at the bulbomembranous junction. The circular muscle fibers of the external sphincter are carefully reflected until the urethral wall is exposed and the connecting tissue plane is identified (Figure 6). The muscle is separated from the urethra along this plane by gentle blunt proximal dissection up to the prostatic apex until healthy urethra for use in the anastomosis is identified (Figures 7,8).

The anastomosis is performed at the prostatic membranous junction with six 5-0 poliglecaprone sutures incorporating the urethral wall, but not the muscle. Stitches are placed at the $12,2,4,6,8$ and 10 o'clock positions. Since the bulb is still attached, the sutures at 2 and 4 o'clock positions need to be transferred counter-laterally to complete and tie the parachute (Figure 9). After knot tying, the ring of sphincter muscle is anchored to the anastomosis site with three or four interrupted sutures (Figure 10). 


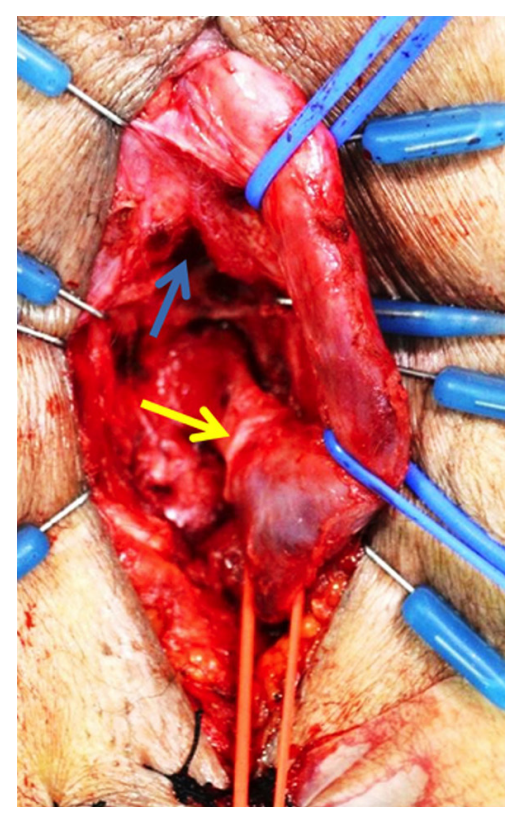

Figure 5 The bulbar urethra has been mobilized and retracted laterally by two vessel loops (blue). The bulbar vessels are retracted posteriorly with another vessel loop (red). The intercrural space has been split in the midline (blue arrow) and the edge of the divided perineal membrane is visible at the bulbomembranous junction (yellow arrow).

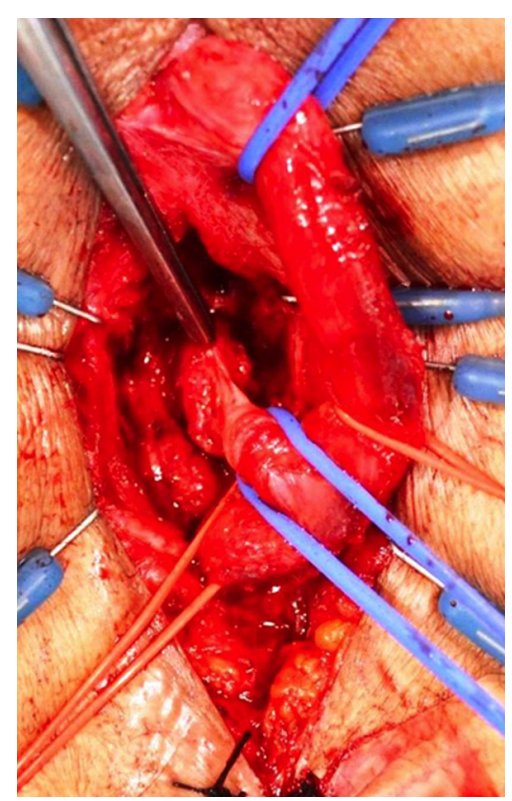

Figure 6 Circumferential incision has been made at the bulbomembranous junction, the urethral wall is exposed, and the surgical plane is identified. Forceps are seen holding the muscle ring of the external sphincter.

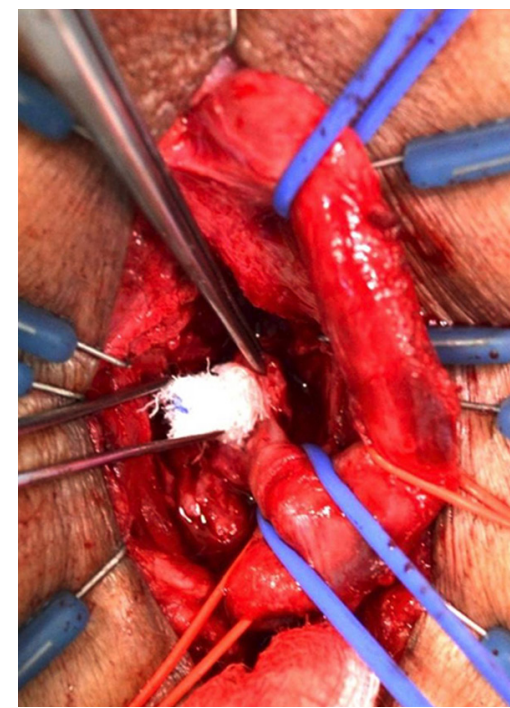

Figure 7 Gentle blunt dissection is used to separate the urethral wall from the external sphincter.

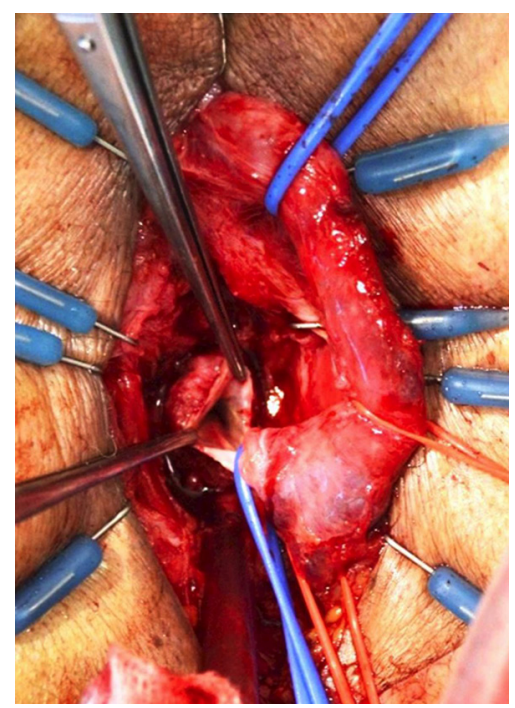

Figure 8 A good caliber proximal urethral end is exposed.

\section{ISBPA outcomes}

We previously reported outcomes of 23 patients treated with ISBPA for membranous or bulbomembranous stenosis which developed following TURP (14 patients) or OSP (9 patients) (54). All 23 patients were voiding stricture-free and 19 patients ( $83 \%$ ) were completely dry or required only one security pad at mean follow-up of 34 months. 


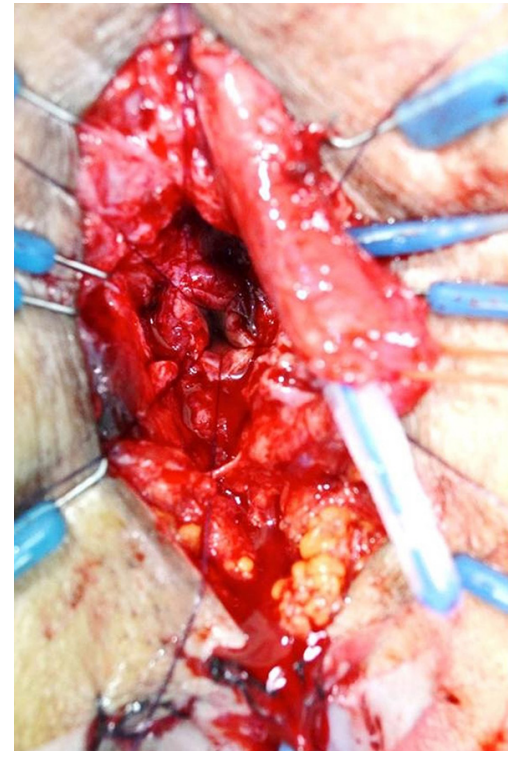

Figure 9 Anastomotic parachute stitches are placed in the normal urethral wall excluding the sphincter muscle.

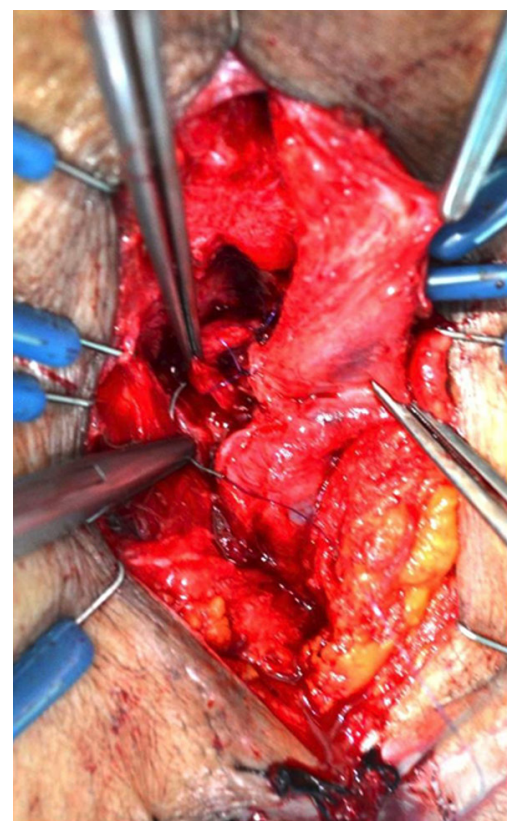

Figure 10 The external sphincter muscle is anchored to the anastomosis with a few interrupted stitches.

\section{PUS following treatment for prostate cancer}

PUS can result as a complication of radical prostatectomy (RP), radiation therapy (RT), focal ablative therapy, or combination therapy for prostate cancer. It can present with involvement of the bulbomembranous urethra, the prostatic urethra, or the $\mathrm{BN}$.

PUS after RP usually present as a VUAS, also known as "BN contracture", while PUS after primary RT or focal ablation most frequently involve the prostatomembranous or bulbomembranous urethra.

Incidence of PUS has been reported as $1-8 \%$, but population-based studies found a higher 10 -year cumulative incidence: RP (19.3\%), RT (9.6\%), RP + external beam RT (25.9\%), and RT + brachytherapy (19.4\%) (55).

PUS after RP typically occurs within the first few months following treatment while RT-associated stenosis presents in a delayed fashion. VUAS rates after robotic assisted RP are lower compared to retropubic RP (5.8\% vs. 14\%), with reported rates as low as $1.1 \%(56)$.

\section{Endoscopic management of VUAS after RP or RT}

While attempts at endoscopic management for PUS following PFUI are typically not advisable, initial management of VUAS is primarily conservative. Urethral dilation with or without periodic self-dilation by the patient has been found to be successful (49-90\%) in RP-associated VUAS patients, particularly for early stenosis development $(57,58)$. For more dense scars, deep cold knife direct vision internal urethrotomy is a second line options with moderate rates of success (37-50\%) (59-61). Collins knife incision or transurethral resection of the scar can be considered for failures, but recurrence is high and there is risk of de novo incontinence (62). Incision with intralesional injection of mitomycin C may improve success (58\%), but severe complications occurred in as many as $7 \%$ of patients $(63,64)$. Recalcitrant failures (3-4 procedures) with or without incontinence should be considered for reconstruction.

\section{Surgical reconstruction of PUS following prostate cancer therapy}

\section{Surgical reconstruction of RP-associated VUAS}

Short VUAS above an intact sphincter, and without previous RT, can be reconstructed with a transabdominal, transpubic re-do vesicourethral anastomosis with a reported $60-83 \%$ success, preserving continence in about $70 \%$ of patients (65) (Figures 11,12).

On the contrary, longer stenosis involving the membranous urethra, patients with previous incontinence, or patients with previous RT require reconstruction 


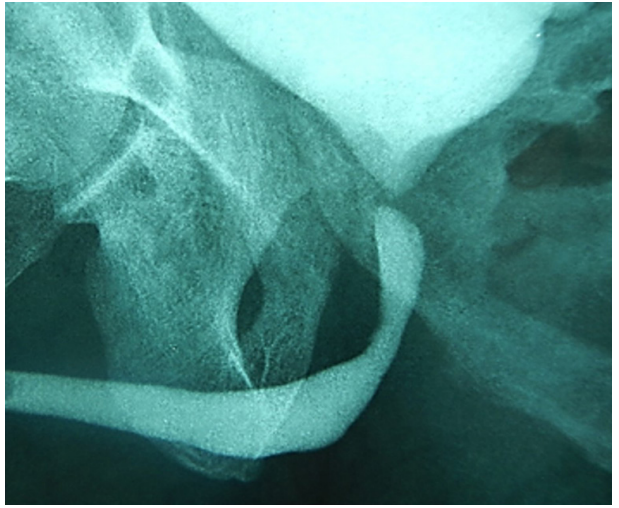

Figure 11 Short VUAS; note the intact membranous urethra and a good suprasphincteric urethral stump. VUAS, vesicourethral anastomotic stenosis.

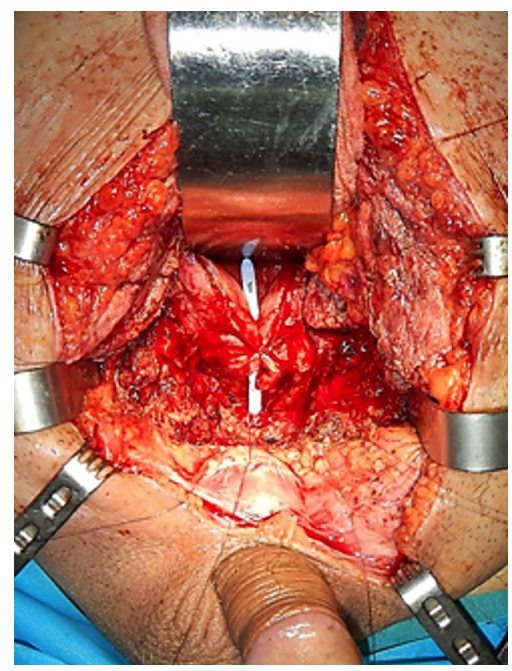

Figure 12 Transpubic vesicourethral re-do anastomosis allows continence preservation.

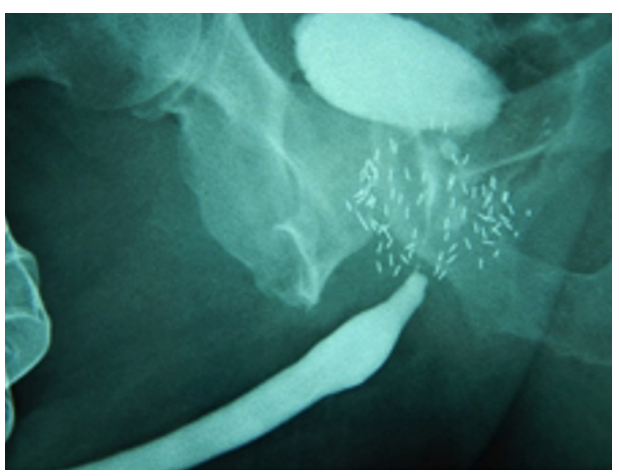

Figure 13 Long prostatic membranous stenosis after prostate brachytherapy.

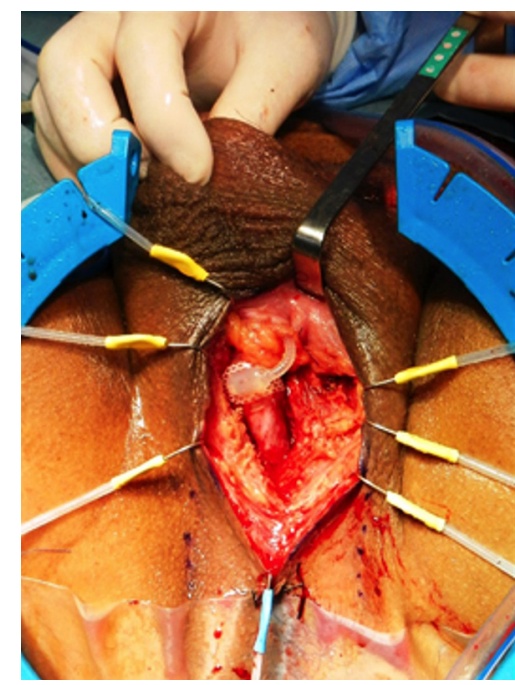

Figure 14 Total incontinence after transperineal bulbo prostatic reconstruction requires a delayed AUS. AUS, artificial urethral sphincter.

with a transperineal anastomotic urethroplasty. In these cases, post-operative incontinence is the rule, so staged placement of an AUS is anticipated. Reported success of the reconstruction is $80 \%$ and continence after AUS is also around $80 \%(66,67)$ (Figures 13,14).

\section{Reconstruction of PUS after primary RT or focal ablation}

PUS following RT is usually more extensive and complex, involving the membranous and/or prostatic urethra. Since the prostate is typically still in situ, the internal sphincter is functional and less incontinence can be expected.

First line therapy is conservative, however more repeated and invasive endoscopic procedures are frequently required and a lower success rate $(40-50 \%)$ is obtained (68). Management of failures entails excision and primary anastomosis with about $70 \%$ success, though there is a $36-50 \%$ risk of de novo incontinence with $15 \%$ of patients requiring an AUS (69).

\section{Conclusions}

Stenosis of the posterior urethra is a very difficult and severe condition that jeopardizes normal bladder emptying, urinary continence, and quality of life. Successful reconstruction is obtainable, but a demanding and complex surgical procedure is often required. As is typical in surgery, 
the best operation is always the first, and failures entail a severe worsening of the ultimate prognosis. A detailed preoperative assessment and surgical plan are essential, as is the surgeon's experience and expertise. Given the infrequent presentation of posterior urethral pathology, it is difficult for the general urologist to obtain the exposure necessary to achieve sufficient experience with the techniques for posterior urethral reconstruction. Therefore, proctored training at experienced tertiary referral centers is strongly advised.

\section{Acknowledgements}

None.

\section{Footnote}

Conflicts of Interest: The authors have no conflicts of interest to declare.

\section{References}

1. Rosenstein DI, Alsikafi NF. Diagnosis and classification of urethral injuries. Urol Clin North Am 2006;33:73-85,vi-vii.

2. Mundy AR, Glass J. BLADDER, PROSTATE AND URETHRA - Male Urethra. In: Standring S. editor. Gray's Anatomy. 39 edition. London: Elsevier Churchill Livingstone, 2008.

3. Jordan GH. Management of Membranous Urethral Distraction Injuries Via the Perineal Approach. In: McAninch JW, editors. Traumatic and Reconstructive Urology. Philadelphia: WB Saunders Company, 1996;393-409.

4. Clegg EJ. The nusculature of the human prostatic urethra. J Anat 1957;91:345-51.

5. MacDiarmid SA, Chapple CR. Surgical management of injuries to the bladder neck. In: Traumatic and reconstructive urology. Philadelphia: WB Saunders, 1996;533-40.

6. Oelrich TM. The urethral sphincter muscle in the male. Am J Anat 1980;158:229-46.

7. Karam I, Droupy S, Abd-Alsamad I, et al. Innervation of the female human urethral sphincter: $3 \mathrm{D}$ reconstruction of immunohistochemical studies in the fetus. Eur Urol 2005;47:627-33; discussion 634.

8. Dalpiaz O, Mitterberger M, Kerschbaumer A, et al. Anatomical approach for surgery of the male posterior urethra. BJU Int 2008;102:1448-51.

9. Shenfeld OZ, Kiselgorf D, Gofrit ON, et al. The incidence and causes of erectile dysfunction after pelvic fractures associated with posterior urethral disruption. J Urol 2003;169:2173-6.

10. Jordan GH. Editorial comment to Shenfeld OZ, Kiselgorf D, Gofrit ON, Verstandig AG, Landau EH, Pode D, Jordan GH, McAninch JW. The incidence and causes of erectile dysfunction after pelvic fractures associated with posterior urethral disruption. J Urol 2017;169:2175. Available online: http://dx.doi.org/10.1016/S00225347(01)69182-1

11. Zuckerman JM, McCammon KA, Tisdale BE, et al. Outcome of penile revascularization for arteriogenic erectile dysfunction after pelvic fracture urethral injuries. Urology 2012;80:1369-73.

12. Iselin CE, Webster GD. The significance of the open bladder neck associated with pelvic fracture urethral distraction defects. J Urol 1999;162:347-51.

13. Dixon CM, Hricak H, McAninch JW. Magnetic resonance imaging of traumatic posterior urethral defects and pelvic crush injuries. J Urol 1992;148:1162-5.

14. Koraitim MM, Reda IS. Role of magnetic resonance imaging in assessment of posterior urethral distraction defects. Urology 2007;70:403-6.

15. Lynch TH, Martínez-Piñeiro L, Plas E, et al. EAU guidelines on urological trauma. Eur Urol 2005;47:1-15.

16. Martínez-Piñeiro L, Djakovic N, Plas E, et al. EAU Guidelines on Urethral Trauma. Eur Urol 2010;57:791-803.

17. Scarberry K, Bonomo J, Gómez RG. Delayed Posterior Urethroplasty Following Pelvic Fracture Urethral Injury: Do We Have to Wait 3 Months? Urology 2018;116:193-97.

18. Morey AF, McAninch JW. Reconstruction of posterior urethral disruption injuries: outcome analysis in 82 patients. J Urol 1997;157:506-10.

19. Cooperberg MR, McAninch JW, Alsikafi NF, et al. Urethral reconstruction for traumatic posterior urethral disruption: outcomes of a 25-year experience. J Urol 2007;178:2006-10; discussion 2010.

20. Biswas S, Gnanasekaran I, Ivatury RR, et al. Exaggerated lithotomy position-related rhabdomyolysis. Am Surg 1997;63:361-4.

21. Bocca G, van Moorselaar JA, Feitz WF, et al. Compartment syndrome, rhabdomyolysis and risk of acute renal failure as complications of the lithotomy position. J Nephrol 2002;15:183-5.

22. Gabrielli A, Caruso L. Postoperative acute renal failure secondary to rhabdomyolysis from exaggerated lithotomy position. J Clin Anesth 1999;11:257-63.

23. Bildsten SA, Dmochowski RR, Spindel MR, et al. The 
risk of rhabdomyolysis and acute renal failure with the patient in the exaggerated lithotomy position. J Urol 1994;152:1970-2.

24. Bascom A, Ghosh S, Fairey AS, et al. Assessment of Wound Complications After Bulbar Urethroplasty: The Impact of a Lambda Perineal Incision. Urology 2016;90:184-8.

25. Webster GD, Ramon J. Repair of pelvic fracture posterior urethral defects using an elaborated perineal approach: experience with 74 cases. J Urol 1991;145:744-8.

26. Marion G. De la reconstitution de l'urètre par urétrorraphie circulaire avec derivation de l'urine. J d'Urol 1912;1:523-38.

27. Paine $\mathrm{D}$, Coombes $W$. Transpubic reconstruction of the urethra. Br J Urol 1968;40:78-84.

28. Waterhouse K, Laungani G, Patil U. The surgical repair of membranous urethral strictures: experience with 105 consecutive cases. J Urol 1980;123:500-5.

29. Koraitim MM. Post-traumatic posterior urethral strictures: preoperative decision making. Urology 2004;64:228-31.

30. Hosseinee J, Rezaei A, Mohammadhoseinee M, et al. Evaluation of supracrural rerouting success rate as a technique for resolution of posterior urethral disruption defects. Urology 2009;6:204-7.

31. Kizer WS, Armenakas NA, Brandes SB, et al. Simplified reconstruction of posterior urethral disruption defects: limited role of supracrural rerouting. J Urol 2007;177:1378-81; discussion 1381-2.

32. Flynn BJ, Delvecchio FC, Webster GD. Perineal repair of pelvic fracture urethral distraction defects: experience in 120 patients during the last 10 years. J Urol 2003; 170:1877-80.

33. Corriere JN. 1-Stage delayed bulboprostatic anastomotic repair of posterior urethral rupture: 60 patients with 1-year followup. J Urol 2001;165:404-7.

34. Fu Q, Zhang J, Sa YL, et al. Transperineal bulboprostatic anastomosis in patients with simple traumatic posterior urethral strictures: a retrospective study from a referral urethral center. Urology 2009;74:1132-6.

35. Tunc HM, Tefekli AH, Kaplancan T, et al. Delayed repair of post-traumatic posterior urethral distraction injuries: long-term results. Urology 2000;55:837-41.

36. Kulkarni SB, Barbagli G, Kulkarni JS, et al. Posterior urethral stricture after pelvic fracture urethral distraction defects in developing and developed countries, and choice of surgical technique. J Urol 2010;183:1049-54.

37. Hosseini SJ, Rezaei A, Mohammadhosseini M, et al. Supracrural rerouting as a technique for resolution of posterior urethral disruption defects. Urol J 2009;6:204-7.

38. Andrich DE, O'Malley KJ, Summerton DJ, et al. The type of urethroplasty for a pelvic fracture urethral distraction defect cannot be predicted preoperatively. J Urol 2003;170:464-7.

39. Koraitim MM. On the art of anastomotic posterior urethroplasty: a 27-year experience. J Urol 2005;173:135-9.

40. Koraitim MM. Predictors of surgical approach to repair pelvic fracture urethral distraction defects. J Urol 2009;182:1435-9.

41. Koraitim MM. Gapometry and anterior urethrometry in the repair of posterior urethral defects. J Urol 2008;179:1879-81.

42. Jordan GH, Eltahawy EA, Virasoro R. The technique of vessel sparing excision and primary anastomosis for proximal bulbous urethral reconstruction. J Urol 2007;177:1799-802.

43. Gomez RG, Campos RA, Velarde LG. Reconstruction of Pelvic Fracture Urethral Injuries With Sparing of the Bulbar Arteries. Urology 2016;88:207-12.

44. Martínez-Piñeiro L, Julve E, Martínez-Piñeiro JA. Topographical anatomy of the penile arteries. Br J Urol 1997;80:463-7.

45. Kishore TA, Bhat S, John RP. Colour Doppler ultrasonographic location of the bulbourethral artery, and its impact on surgical outcome. BJU Int 2005;96:624-8.

46. Lumen N, Hoebeke P, Troyer BD, et al. Perineal anastomotic urethroplasty for posttraumatic urethral stricture with or without previous urethral manipulations: a review of 61 cases with long-term followup. J Urol 2009;181:1196-200.

47. Koraitim MM. Assessment and management of an open bladder neck at posterior urethroplasty. Urology 2010;76:476-9.

48. Culty T, Boccon-Gibod L. Anastomotic urethroplasty for posttraumatic urethral stricture: previous urethral manipulation has a negative impact on the final outcome. J Urol 2007;177:1374-7.

49. Corriere JN Jr, Rudy DC, Benson GS. Voiding and erectile function after delayed one-stage repair of posterior urethral disruptions in 50 men with a fractured pelvis. J Trauma 1994;37:587-9; discussion 589-90.

50. Singh BP, Andankar MG, Swain SK, et al. Impact of prior urethral manipulation on outcome of anastomotic urethroplasty for post-traumatic urethral stricture. Urology 2010;75:179-82.

51. Bhagat SK, Gopalakrishnan G, Kumar S, et al. Redourethroplasty in pelvic fracture urethral distraction defect: 
an audit. World J Urol 2011;29:97-101.

52. Wadhwa SN, Chahal R, Hemal AK, et al. Management of obliterative posttraumatic posterior urethral strictures after failed initial urethroplasty. J Urol 1998;159:1898-902.

53. Shenfeld OZ, Gofrit ON, Gdor Y, et al. Anastomotic urethroplasty for failed previously treated membranous urethral rupture. Urology 2004;63:837-40.

54. Gomez R, Castaño JC, Velarde L, et al. PD44-01 reconstruction of bulbo-membranous urethral strictures after surgery for benign prostatic hiperplasia with preservation of continence. J Urol 2016;195:e998.

55. Jarosek SL, Virnig BA, Chu H, et al. Propensity-weighted long-term risk of urinary adverse events after prostate cancer surgery, radiation, or both. Eur Urol 2015;67:273-80.

56. Msezane LP, Reynolds WS, Gofrit ON, et al. Bladder neck contracture after robot-assisted laparoscopic radical prostatectomy: evaluation of incidence and risk factors and impact on urinary function. J Endourol 2008;22:377-83.

57. Geary ES, Dendinger TE, Freiha FS, et al. Incontinence and vesical neck strictures following radical retropubic prostatectomy. Urology 1995;45:1000-6.

58. Erickson BA, Meeks JJ, Roehl KA, et al. Bladder neck contracture after retropubic radical prostatectomy: incidence and risk factors from a large single-surgeon experience. BJU Int 2009;104:1615-9.

59. Surya BV, Provet J, Johanson KE, et al. Anastomotic strictures following radical prostatectomy: risk factors and management. J Urol 1990;143:755-8.

60. Dalkin BL. Endoscopic evaluation and treatment of anastomotic strictures after radical retropubic prostatectomy. J Urol 1996;155:206-8.

61. Brede C, Angermeier K, Wood H. Continence outcomes

Cite this article as: Gomez RG, Scarberry K. Anatomy and techniques in posterior urethroplasty. Transl Androl Urol 2018;7(4):567-579. doi: 10.21037/tau.2018.03.05 after treatment of recalcitrant postprostatectomy bladder neck contracture and review of the literature. Urology 2014;83:648-52.

62. Popken G, Sommerkamp H, Schultze-Seemann W, et al. Anastomotic stricture after radical prostatectomy. Incidence, findings and treatment. Eur Urol 1998;33:382-6.

63. Vanni AJ, Zinman LN, Buckley JC. Radial urethrotomy and intralesional mitomycin $\mathrm{C}$ for the management of recurrent bladder neck contractures. J Urol 2011;186:156-60.

64. Redshaw JD, Broghammer JA, Smith TG 3rd, et al. Intralesional injection of mitomycin $\mathrm{C}$ at transurethral incision of bladder neck contracture may offer limited benefit: TURNS Study Group. J Urol 2015;193:587-92.

65. Pfalzgraf D, Beuke M, Isbarn H, et al. Open retropubic reanastomosis for highly recurrent and complex bladder neck stenosis. J Urol 2011;186:1944-7.

66. Simonato A, Gregori A, Lissiani A, et al. Two-stage transperineal management of posterior urethral strictures or bladder neck contractures associated with urinary incontinence after prostate surgery and endoscopic treatment failures. Eur Urol 2007;52:1499-504.

67. Andrich DE, Mundy AR. Non-transecting anastomotic bulbar urethroplasty: a preliminary report. BJU Int 2012;109:1090-4.

68. Fuchs JS, Hofer MD, Sheth KR, et al. Improving Outcomes of Bulbomembranous Urethroplasty for Radiation-induced Urethral Strictures in Post-Urolume Era. Urology 2017;99:240-5.

69. Hofer MD, Zhao LC, Morey AF, et al. Outcomes after urethroplasty for radiotherapy induced bulbomembranous urethral stricture disease. J Urol 2014;191:1307-12. 